\title{
No compasso da cultura: uma leitura sócio-cultural do poema "Dança", de Mário de Andrade
}

\author{
Maria de Fátima Soriano de Lima/Pós-Graduanda (UFAL)
}

Para os modernistas, o aspecto do aproveitamento da oralidade no texto literário foi uma grande meta e de onde decorreu todo um comportamento para aceitaçào e batismo de uma "língua brasileira". Se o povo já falava "brasileiro", faltava à literatura dar o grande passo, embora na opinião de Mário de Andrade, escritores considerados mestres do passado como Raimundo Correia, Olavo Bilac, Francisca Júlia e outros já tivessem tentado experiências no mesmo sentido.

A luta de Mário para renovar a cultura brasileira começou com a Semana de Arte Moderna, evento do qual participou ativamente. Ele encarava sua atividade cultural como missào, querendo ser útil no processo de construçào de um Brasil que mudava social, política, econômica e culturalmente. Em seus estudos e correspondências, Mário revelou a preocupaçào com a fidelidade no registro da cultura popular.

Se Macunaima (1928) foi uma obra-prima na fase ousada do autor, que revolucionou a nossa literatura com o seu "herói sem nenhum caráter", sua obra poética Remate de Males (1930) faz parte da fase madura do autor. É a fase da consolidaçào.

Em Remate de Males há uma preocupação com o sócio-cultural brasileiro (Há uma busca por situar o social para se compreender o Brasil). Essa obra poética apresenta poemas que versam sobre o "sincretismo" cultural (cumo em Eu sou trezentos...); sobre o aspecto social brasileiro da época (como em DANÇA, poemr que analisaremos mais adiante); sobre a mulher a ser amada, recorrendo-se à forma e ao conteúdo populares (como em Moda do Corajoso, Cantiga do Ai e Lenda das Mulheres do Peito Chato); sobre o atraso do Brasil em vista do progresso emergente da época: isto é perceptível no poema Louvação da Tarde, texto em que funde, de forma sutil, o lírico e o prosaico: "o doce respirar do forde se une/ Aos gritos pontiagudos das graúnas".'

No poema Maria, que aborda a temática popular do amor, aproximando o santo do profano. O popular se configura, também, em outros poemas, fato este que demonstra o teor cultural presente na obra Marioandradina. A ligaçào com esta

'do poema "Louvação da Tarde" da coletânea Remate de Males de Mário de Andrade. 5 a ed, São Paulo, Martins: 1979. 
forma/conteúdo popular corporificam-se, ainda, em Improviso do Mal da América, A Advinha e Improviso do Rapaz Morto.

Como se vê, a multiplicidade temática de Mário de Andrade faz dele uma autoridade no tocante aos estudos antropológicos e culturais, daí a contribuiçào de sua obra literária para se compreender a cultura brasileira a partir de produtos literários. Este trabalho se restringe a analisar o poema "DANÇA" ? como sendo uma metáfora da condiçào sócio-cultural brasileira; tomamos como base para nossa análise o conceito de cultura brasileira de Alfredo Bosi (1996). Para esse teórico, as várias manifestaçòes culturais explicitadas pelos grupos sociais assentados no chào brasileiro, com as inúmeras contribuiçòes culturais advindas das diversas categorias sociais, juntam-se e formam o que chamamos de identidade cultural brasileira. E para Mário a busca de uma identidade cultural brasileira sempre foi uma constante. O muito fazer, o cterno criar, seus estudos etnográficos, todos os seus passos podem ser acompanhados nos originais que conservou em seu arquivo. Esse revolucionário e estudioso atento da tradiçào, que com o modernismo amplia os horizontes da literatura brasileira, levantando a bandeira da liberdade de açào, a busca de uma arte só nossa, também ajudou-nos a decifrar o passado cultural brasileiro e a contribuiçào da cultura popular, diluindo as fronteiras entre o urbano e o rural, o popular e o erudito, vendo-nos complexos como somos.

No poema "I $\wedge$ NCSA", Mário fez brotar toda sua criatividade quando relacionou o poema à sociedade, dançando, isto é, em movimento para se formar. Dizemos isto porque o poema de que falamos, em suas várias instâncias, apresentase, formalmente falando, com versos deslocados, ora aproximando-se da margem esquerda da folha, ora da margem direita; ora concentrando-se no centro, ora aproximando-se de todas as margens, provocando olhares nào lineares sobre a sua composiçào: os versos se movimentam, no poema, como se estivessem literalmente dançando, movimentando-se em passos cadenciados, o que caracteriza este poema como sendo um dos da colctânea Remate de Males que mais aproxima o seu ritmo do aspecto musical. É sabido que o vocábulo DANÇA tem como conceito "a cadência de passos ou saltos, ordinariamente ao som e ao compasso da música”. Assim podemos ver que Mário relacionou esse poema ao movimento que a vida dá na sua trajetória de altos e baixos como se fosse uma roda gigante, em movimento constante. É bom lembrar que o vocábulo DANÇA também tem outros sentidos: negócio intricado, manifestaçào cultural, liberaçào de energia e outros'

\footnotetext{
2 Poema da coletânea Poesias Completas (Remate de Males), de Mário de Andrade, 5a ed, São Paulo: 1979 .

'FERREIR.A, Aurélio Buarque de Hollanda. Pequeno dicionáro brasileiro da lingua portuguesa, 13' ed, Rio de Janeiro: 1980, Verbete D.ANC.. p. 360.

'C.f. o mesmo verbete anteriormente citado no mesmo dicionário aludido, na p. 360.
} 
O poema apresenta nove instâncias com variedade de tamanho dos versos. O espaço do texto é multiforme, nào é regular. Nele se observa o ludismo, o jogo, a brincadeira que Mário faz com as palavras; é a DANÇA dos versos e das estrofes, como podemos verificar nos versos abaixo:

"Filha, tu sabes... que hei-de-fazer!

Nós todos somos assim.

Eu sou assim.

Tu és assim.

Dançam os pronomes pessoais.

Nunca em minuetes! Nunca em furlanas!

EU

ELE

TU

NÓS

ELES

VÓS...
Nào paro.
Nào paras.
Sucedem quadrilhas...
Gatunos!
Assassinos!
Ciganos!
Judeus!
Quebras formidáveis!’’5

Nos versos supra citados, podemos observar o jogo com as palavras que o autor de Macunaima faz. Brinca com as palavras em ritmo de dança, jogando-as pra lá, pra cá. Brincando com os pronomes pessoais, nesse vai e vem com os vocábulos. Esse aspecto visual do texto causa estranhamento. Isso só foi permitido graças ao modernismo que pregava a liberdade na forma e no fundo e o livremetrismo na poesia. Foi realmente um movimento geral de libertaçào, libertador contra o passado, contra o sentimentalismo, contra regras e modelos. Por isso, a contribuiçào de Mário para a inovaçào da literatura brasileira foi valiosa: ele sabia ser ousado. Sua criatividade cra intensa - tomemos como exemplo a criaçào de

"Instância III do poema DANÇ.A. 
Macunaima que tanto causou polêmica. O vocábulo quadrilha(s)" tem vários sentidos: dança junina (manifestaçào cultural); cavalhada; bando de ladròes, corja, multidào. Lembra também a violência, o terror nas palavras que se seguem, denotadoras de categorias sociais marginalizadas: Gatunos! Assassinos! Ciganos! Judeus! Os judeus e os ciganos sempre foram perseguidos pelo preconceito, até mesmo nos dias atuais.

Nos versos a seguir (instância I) o autor faz uma analogia, no poema, do progresso social em movimento com a forma do texto que apresenta:

"pressa

apertos

automóveis

bamboleios

Pincho ariscos de gritos

Bondes sapateando nos trilhos..."

São palavras que sugerem o movimento ou o avanço tecnológico da época: pressa, é o corre-corre da vida; apertos, pode ser visto em dois sentidos: o aperto dos bondes ou o aperto da dança da vida (financeiro). Aquela que se dança pela sobrevivência. Os vocábulos AUTOMÓVEIS, TRILHOS, BONDES representam $\mathrm{o}$ avanço da tecnologia no início do século XX. O surgimento de uma nova concepção estética de valores. A máquina, a velocidade, a técnica passaram a ser temas artísticos. No modernismo europeu, sobretudo com o Futurismo, o automóvel estava ligado à velocidade, como sinal da nova era. Esse vocábulo já foi objeto de poesia em diversos poemas de Marinetti, como em "ao automóvel de corrida", "ao Manifesto Futurista"” (1909) e posteriormente, no poema do próprio Mário de Andrade, "louvaçào da tarde" ". É visível que o poeta quis mostrar o avanço da tecnologia, do progresso, bailando em versos, em ritmo de dança, a luta do cotidiano da época. As charretes foram substituidas pelos bondes e pelos automóveis, dependendo da classe social que cada um ocupava. O lugar da elite nào era nos apertos dos bondes e sim, nos automóveis. $\mathrm{O}$ aperto do bonde era para a classe menos favorecida.

$\mathrm{Na}$ instância II, encontramos os seguintes versos:
"Meu cigarro está aceso
O fumo esguicha,
O fumo sobe,

\footnotetext{
"FERREIRA, Aurélio Buarque de Hollanda. Pequeno dicionário brasileiro da lingua portuguesa, 13" ed, Rio de Janeiro: 1980, verbete quadrilha p. 1000.

${ }^{7}$ CANDIDO, Antonio. O discurso e a cidade. São Paulo: Duas Cidades, 1993.

"Poema da antologia poética Remate de Males (1930)
} 
O fumo sobe ao bem e ao mal...

O bem e o mal, que coisas sérias!

Riqueza é bem.

'Tristeza é mal.

Desastres,

Sangue

Tiros

Doença

Dança!...”

O poema traduz a problemática de uma cidade grande cuja violência, tristeza, sangue, tiros, doença, riqueza, bem e mal bailam na dança do cotidiano. É a realidade da violência da cidade, traduzida através de versos. Verdadeira onda de marginalidade e violência pairando por todos os cantos da cidade. Desastres, sangue, tiro, doença são conseqüências dos vícios que geram todos estes vocábulos. $E$ mais uma vez o vocábulo "DANÇA" está presente no poema. É a dança da vida do cotidiano. É o ser obrigado a conviver com a problemática da vida e saber driblar todos os impasses que trilham no caminho. É ser obrigado a conviver com estes problemas que já se tornaram corriqueiros. E Mário, sendo múltiplo como é, soube jogar nesse poema vários temas que envolveram a realidade da sua época e que ainda persistem nos dias de hoje.

A economia da época também foi traduzida no espaço poemático marioandradino de Remate de Males.

O suporte retórico utilizado para representá-la pode ser observado na instância II do poema em estudo, como se verifica nos versos abaixo:

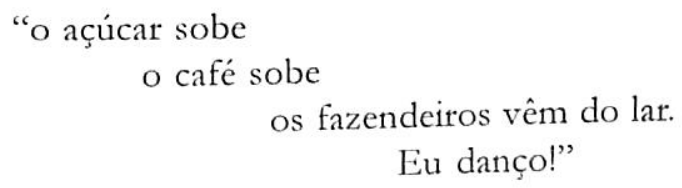

Muito criativo é o jogo de palavras que o grande poeta do modernismo faz, nos permitindo perceber o movimento de subida e descida da economia brasileira: brincando com os versos, tentou passar a idéia de uma ladeira ou escada, jogando assim com o fator econômico nos seus altos e baixos.

Ao citar "o açúcar sobe", é bom recordar que o açúcar brasileiro, que até 1830 era o produto da pauta das exportaçòes do país, foi perdendo sua posiçào privilegiada. Diante da competiçào internacional, nosso açúcar passou a ser vendido, basicamente, no mercado interno brasileiro. Os grandes paises capitalistas davam preferência ao açúcar produzido em territórios diretamente dominados por cles. A 
partir dai, o Nordeste deixou de ser o centro da economia brasileira que entrou em decadência.

A respeito do café, vale a pena lembrar que Sào Paulo era o centro das mais variadas atividades. O café tomava todo o tempo dos bandeirantes tradicionalistas que se interessavam também pelo progresso do país. Esses homens voltados para a lavoura do café formaram a elite do movimento. Mas, a classe média também crescia e lutava para atingir um certo grau de intelectualidade, visto que "estudar fora" tornava-se quase impossível. As ferrovias, a instalaçào dos serviços públicos urbanos, companhias de iluminaçào, transportes urbanos, usinas hidroelétricas e telégrafos, entre outras melhorias, foram realizadas com o capital de cafeicultores ou de estrangeiros. Para estes, a esperança de lucro se fundava no café, pelo menos indiretamente.

Quando Mário cita no poema "o café sobe", percebe-se que quando o preço do café está $\mathrm{cm}$ alta, instaura-se a crise no meio popular. Os fazendeiros também em crise porque nào conseguem vender o produto café a preço em conta, desfazem-se de seus lares (hipotecam suas casas) como é representado no verso "vêm do lar", esse jogo criativo do nosso autor que brinca com as palavras, em outros sentidos quis dizer (vendem o lar). As conseqüências sào trágicas, pois fere a economia do país. Mário compara a economia brasileira com o elevador, no movimento de subida e descida constante, como a bolsa de valores que lida com o alto e baixo.

Quando o eu-lírico afirma nesse verso, "eu danço", ele dança driblando as dificuldades financeiras e todas as suas conseqüências. É uma verdadeira maratona que para alcançar a vitória passa por inúmeros obstáculos no caminho. Se naquela época (1924), o poeta dançava em busca da sobrevivência, nào é diferente nos dias atuais. Todos nós dançamos, metaforicamente, driblando os impasses, em busca de melhores condiçòes de vida. A crise econômica que ora atravessa o nosso país é um verdadeiro caos.

A bolsa de valores e seus movimentos oscilantes fazem parte dessa dança que Mário soube empregar muito bem nesse poema, para caracterizar a realidade sócio-cultural do país. Veja os versos abaixo:

\footnotetext{
"A Bolsa revira

Reviram-se as bolsas".
}

Mário sempre se preocupou com os problemas do Brasil: Ele cantou o amor pela cidade de Sào Paulo, pelos brasileiros, pelo Nordeste. O poeta identifica esses problemas ao longo dos versos e nos informa isso através do movimento, similar à dança, dos versos. E no compasso dessa dança, encontramos um fazer pótico bem diferente e muito criativo. É toda uma sociedade voltada para uma 
carência. O Eu lírico tece nesse poema o retrato de um Brasil problemático. A dança, marca registrada da cultura popular, está presente em todo o poema. A realidade do Brasil nos é revelada através dos seus versos. Em todo o poema desenrola-se uma espécie de balé do retrato do Brasil, jogando, rítmica e semanticamente através dos versos, alusòes à economia brasileira e a outros temas. Em forma de dança, de molejo, o eu lírico apresenta os problemas da nossa sociedade multicultural e multi-racial. Em dança sào colocadas em cena parte dos conflitos que atravessam o Brasil e o seu povo.

Podemos ver nos versos abaixo a proposta de um Brasil multicultural para Mário:

A vida é tào curta!

Quem tem certeza do amanhà!

Lourenço de Medecis?...

Florença delira,

Paris queima

Viena dança,

Berlim ri...

E New York abençoa o Jazz universal.

Negros de cartola

Turcos de casaco

Montecarlo e Caldas e Copacabana

Tudo é um caxambú!

Segundo BHABHA (1998), a tradiçào é móvel e os locais da cultura sào vários. As identidades culturais estào sempre em contato com as outras. Florença, Paris, Viena, Berlim, New York, Copacabana sào "as outras". Segundo HALL (1997: 99) o hibridismo - a fusào de culturas que se encontram para dar origem a outras mesclando costumes, sempre em busca de uma identidade nacional - ć a marca pela qual se rege o mundo contemporâneo, pois as fronteiras culturais deslizam de tal forma que há a tendência, hoje, da junçào de grupos identitários diferentes em um mesmo espaço como ocorre no poema citado.

Nào podemos afirmar que um certo local é puramente brasileiro porque segundo BHABHA (idem), há uma quebra de fronteiras e essa quebra favorece o surgimento de culturas híbridas. Assim sendo, a cultura é um complexo que dialoga com outras culturas, como também assim o entendem BOSI (idem) e R.AMA (1975).

E no compasso dessa dança, sem perder seu ritmo, Mário continua brincando com os versos e propòe um Brasil multicultural. Neste poema, o poeta modernista nào fica cego em relaçào aos limites móveis do complexo cultural brasileiro. Usando a metáfora da dança, ele representa o Brasil em vários aspectos. 
Nos versos seguintes temos um exemplo de vários estratos culturais em cruzamento: a cultura enciclopédica cruza-se com alusòes as figuras populares no poema como um traço da formaçào de nossa cultura, que aparece na matéria verbal do poema:

Meu alfaiate tem mais fregueses

Nào há canalha sem virtude.

Nào há vitoriosos sem desonra.

Entro nos teatros lendo jornais.

Converso pouco e escuto muito.

Falo francês...

Leio em vernáculo Tristram Shandy.

conheço Freud e Dostoievsky.

compro as revistas do Brasil.

E

Principalmente

Sei enramar meu ditirambo,

Sei guspir um madrigal!

Nos versos acima, há uma representaçào desse estado de cultura enciclopédica pela qual o brasileiro se rege (bem como as sociedades letradas de hoje): a partir de uma linguagem irônica, o jornal, o falar vernáculo e francês; o ler Shandy, Freud, Dostoievsky sào recursos poemáticos utilizados (alusivamente) por Mário de Andrade, via eu lírico, para demonstrar essa "falta de intelectualidade" brasileira e, para adquirir esse aspecto "erudito", deglute antropofagicamente a cultura do outro, recebendo, assim, a influência de outros discursos para a construçào de um discurso próprio.

Por tudo que foi exposto e analisado, percebemos que o poeta Mário de Andrade contribuiu de forma sistemática para a formação de uma representaçào densa da cultura brasileira .

Embora já se tenha falado muito acerca da obra marioandradina, é fato relevante para os estudos culturais brasileiros outros olhares que buscam novos teores, ou ampliem os já desenvolvidos, para que a cultura do nosso país sinta a contribuiçào deste escritor para um embasamento teórico-cultural do que seja, realmente, cultura brasileira (e cultura popular brasileira) e sua representaçào.

Segundo Rama (idem: 75) "é o autor quem se reintegra à comunidade lingǘstica própria, falando de dentro dele, com uso fluente de seus recursos idiomáticos". Portanto é possível observar que em Remate de Males há uma apropriação do discurso lingüístico oral pelo escritor. O poeta adentra-se também no meio 
cosmopolita e reflete sobre seus vários estratos culturais brasileiros.

O conceito de transculturaçào tomado emprestado de Ortiz por RAMA (ibidem) contribui, neste estudo, para tornar relevante o aspecto transculturador marioandradino na obra Remate de Males e associamos a esse conceito a noçào de "identidade móvel" desenvolvido por HALL (idem), pois assim podemos compreender Mário de Andrade traduzindo na obra aspectos culturais em movimentaçào e híbridos, como ocorreu na formaçào da cultura brasileira.

Como se mostrou, dança e uma chamada para a problemática de um país que busca sua identidade nacional. Nesse poema ele é múltiplo porque aborda vários temas, usando a metáfora da dança, ele baila diante dos problemas da sociedade brasileira. Ele foi um grande colaborador da cultura popular brasileira.

Durante todo o poema, Mário usou a dança como metáfora da vida cultural brasileiras; de ambas retira a noçào de mobilidade, introduzindo no espírito do leitor uma forma de consciência que rejeita o cristalizado, o real como categoria imóvel.

Assim se percebe a contribuiçào valiosa desse autor para a representaçào artística da cultura brasileira obrigando-nos a crer que as vozes de Mário na obra em questào, sào vozes de uma cultura em permanente mobilidade. 


\section{Referências bibliográficas}

BHABHA, HOMI K. Locais da cultura. In: - O local da cultura.

Tradução de Myriam Ávila et al. Belo Horizonte: Ed. da Universidade/UFMG, 1998. p. $19-42$.

BOSI, Alfredo. Cultura brasileira e culturas brasileiras. In: Dialética da colonização. 3. ed. Sào Paulo: Cia. das Letras, 1996. p. 308-345.

HALL, Stuart. 4 identidade cultural na pós-modernidade. Tradução de Tomaz Tadeu da Silva e Guacira Lopes Louro. Rio de Janeiro: DP\&A Ed., 1997.

RAMA, Angel. A transculturaçào na narrativa latinoamericana. In: Cadernos de Opinão, 1975. 